\title{
Weather satellite woes
}

\section{Washington}

WITH two of its three major satellite programmes in trouble, the US National Oceanic and Atmospheric Administration (NOAA) is facing an unpleasant predicament in the near future.

If the satellites do not get back on track, NOAA could find it difficult to know how to provide weather and other remote sensing data over the next few years. Without those data, US weather forecasters could find themselves short of the necessary information to make their predictions, and environmental scientists who depend on Landsat satellites to study vegetation could find their research stalled.

Among NOAA's satellite programmes, the next generation of US geostationary weather satellites is badly behind schedule, way over budget and not even working properly. Meanwhile, the planned seventh satellite in the Landsat series is threatened by a lack of funds. Only NOAA's polar orbiting weather satellite programme is not a matter for concern.

The most immediate concern centres on the GOES-NEXT series of five geostationary weather satellites. Unless the National Aeronautics and Space Administration (NASA), which hired contractors to build the satellites, can convince NOAA officials by the end of this month that last-minute design faults will not further delay the programme, NOAA may be forced to find alternative ways to gather data for use by the US National Weather Service.

The first GOES-NEXT satellite was originally due for launch in 1989 , but the most optimistic launch date now is late 1992. The delays have caused the programme's budget to spiral from $\$ 578$ million to more than $\$ 1,100$ million assuming that there are no further difficulties. That seems unlikely, however, now that NASA has informed NOAA officials that space-simulation tests in a vacuum and at low temperature have revealed faults in the detectors and circuitry of the satellites' imaging system. "There is a credibility problem" with NASA's optimistic launch schedule, says Thomas Pyke, NOAA assistant administrator in charge of satellites and information services.

If GOES-NEXT is delayed too much, it could leave the United States without adequate satellite coverage for weather forecasting. Since the imager on the GOES- 6 failed in 1989, there has been only one geostationary satellite, GOES-7, hovering over the United States. Pyke says that GOES-7 should continue giving reasonable data until 1995, and that the European Meteosat-3 will be moved westward in August to give better coverage of weather systems brewing in the Atlantic.
But any further slippage in the GOESNEXT schedule may force NOAA to look elsewhere for its next geostationary weather satellite, he says. Purchasing a satellite from European manufacturers, or simply ordering a replica of the existing GOES-7 are among the options being considered.

Pyke admits that the present problems stem in part from the decision, taken by jointly by NOAA and NASA in the early 1980 s, to build the GOES-NEXT satellites to an untried specification. (The satellites are three times larger than their predecessors, equipped with imagers covering a broader range of wavelengths.) Dan Tarpley, from NOAA's satellite research laboratory, observes that the delays and instrument problems would have been less serious for an experimental NASA satellite, but NOAA's operational weather satellites "have to work, and have to go up on time".

Compared to the GOES-NEXT fiasco, the long-established Landsat terrestrial imaging programme is superficially healthy. Landsats 4 and 5 are both still functioning, and the sixth satellite in the series is scheduled for launch in July 1992. But the programme's future management and continued funding is in doubt.

Shortly after the Landsat programme was transferred from NASA to NOAA in 1983, then-President Ronald Reagan decreed that Landsat should be a commercial operation, eventually financing itself through the sale of its images, which retail at several thousand dollars a frame. The anticipated market, however, has failed to materialize, and despite assurances from the US Administration that Landsat 7 will be funded, so far nothing has appeared in a presidential budget request. In an attempt to prevent a gap in Landsat imaging after the sixth satellite fails around 1997, Representative George Brown (Democrat, California), chairman of the House Science, Space and Technology Committee, launched a bill in May to authorize funds from the 1992 budget to begin work on Landsat 7. When the 1992 budget appropriations bill left the House, \$30 million was earmarked for Landsat 7 , and Brown's staff hope that more may be added in Senate in the coming weeks.

But if Landsat is to have a sound financial future, it may be necessary to revamp thoroughly the programme's management. Many observers see NOAA as a strange home for Landsat, because the terrestrial images produced by the satellites have little connection with NOAA's responsibility for the oceans and atmosphere. Both Brown's committee and the National Space Council are looking at the possibility of setting up a joint programme office run and financed by all the agencies that are interested in Landsat data.

Securing the long-term future for the Landsat programme would be easier if the diverse Landsat data user community could agree on a preferred specification for Landsat 7's instruments. The present Landsat satellites can resolve images down to 30 metres at ground level, but William James, director of the Defense Mapping Agency, told a joint hearing of the House Committees on Science and Intelligence last month that the military could make better use of the data if Landsat images had a resolution of less than 5 metres.

Such fine resolution would actually hamper the work of environmental scientists using Landsat images to study vegetation cover. Barry Rock of the University of New Hampshire said at the same hearing that his studies of acid rain damage to Eastern European forests would be impossible with 5-metre resolution. Patches of damaged forests would then be indistinguishable from shadowing in the canopy, he said.

Peter Aldhous

INDIA

\section{Sterilized dogs, bulls will keep their libido}

\section{New Delhi}

INDIA plans to sterilize stray dogs and 'scrub' bulls with an animal birth control vaccine developed at the National Institute of Immunology in New Delhi.

A single injection makes male animals permanently aspermic, with the sperm count in semen dropping to zero within four weeks, the institute claims. The sterility produced is permanent and the animal does not lose libido. The cost of sterilizing the animal is said to be less than one rupee.

The drug controller of India has given "new drug authorization" for this vaccine after extensive trials for efficacy, safety acceptability in bulls, buffaloes, dogs and rams. It will be marketed under the trade name Talsur and has been licensed to a public sector company in Bangalore.

According to institute director G. P. Talwar, the Talsur vaccine will help the rabies control programme as well as the current campaign to boost milk production in cows through artificial insemination. Stray dogs will receive a single injection to stop their proliferation, ending the current inhumane practice of capturing and killing them to prevent rabies. Sterilizing scrub bulls - wild bulls with usually inferior genetic characteristics - should improve the artificial insemination programme by ending the current problem of scrub bulls impregnating cows before arrival of semen from semen banks. $\quad$ K. S. Jayaraman 